\title{
Assessing urban atmospheric environmental efficiency and factors influencing it in China
}

Kai Liu ( $\square$ liukaisdnu@163.com )

Shandong Normal University

Xiaoyu Wang

Shandong Normal University

Zongbin Zhang

Shandong Normal University

\section{Research Article}

Keywords: Urban atmospheric environmental efficiency, super-efficiency slacks-based measure, spatial autocorrelation, Geodetector

Posted Date: May 14th, 2021

DOI: https://doi.org/10.21203/rs.3.rs-460589/v1

License: @ (i) This work is licensed under a Creative Commons Attribution 4.0 International License.

Read Full License

Version of Record: A version of this preprint was published at Environmental Science and Pollution Research on August 2nd, 2021. See the published version at https://doi.org/10.1007/s11356-021-156927. 
Assessing urban atmospheric environmental efficiency and factors influencing it in China

Kai Liu ${ }^{\mathrm{a}, b^{*}}$, Xiaoyu Wang ${ }^{\mathrm{a}}$, Zongbin Zhang ${ }^{\mathrm{c}^{*}}$

${ }^{a}$ College of Geography and Environment, Shandong Normal University, Jinan 250358, China

${ }^{\mathrm{b}}$ Collaborative Innovation Center of Human-Nature and Green Development in Universities of Shandong, Shandong Normal University, Jinan 250358, China

${ }^{c}$ School of Economics, Shandong Normal University, Jinan 250358, China

*Corresponding author.

E-mail address: liukaisdnu@163.com (Kai Liu); wxyyzw0903@163.com (Xiaoyu

Wang); zhangzongbin429@163.com (Zongbin Zhang).

Highlights:

The urban atmospheric environmental efficiency in China shows an upward trend.

Urban atmospheric environmental efficiency is highest in Eastern China and lowest in Western China.

Urban atmospheric environmental efficiency has a significant global spatial autocorrelation.

High-high and low-low are main types of efficiency in local spatial autocorrelation. Population density, industrialization, and technology influence this efficiency.

Abstract: With rapid urbanization and industrialization in developing countries, cities have become the major sources of air pollution. Studying urban atmospheric environmental efficiency has important reference value for the prevention and control of air pollution. This study used data from 267 cities in China between 2001 and 2016 to assess the urban atmospheric environmental efficiency using the super-efficiency slacks-based measure model, to test the spatial characteristics of urban atmospheric environmental efficiency using the spatial autocorrelation method, and to identify factors influencing it using the Geodetector. The results are as follows: (1) The atmospheric environmental efficiency of most cities in China is increasing. The 
average efficiency in the entire country exhibits an upward "wavy" trend. The average urban atmospheric environmental efficiency in Eastern China is the highest and that in Western China is the lowest. (2) The urban atmospheric environmental efficiency exhibits the characteristic of global spatial autocorrelation, and high-high and low-low are the main types of efficiency in local spatial autocorrelation. (3) Population density, industrialization, and science and technology are the main factors influencing urban atmospheric environmental efficiency.

Keywords: Urban atmospheric environmental efficiency; super-efficiency slacks-based measure; spatial autocorrelation; Geodetector

\section{Introduction}

Since the Reform and Opening Up in 1978, China has witnessed large-scale economic growth. Its gross domestic product (GDP) increased from 367.87 billion yuan in 1978 to 99086.51 billion yuan in 2019 (National Bureau of Statistics of China, 2020), and it has been the second-largest economy in the world since 2010. With increasing economic growth, remarkable progress has been made in optimizing the economic structure, infrastructure construction, urbanization, foreign trade, science and technology, and improving the living standards of the people. As in other developing countries, extensive and inefficient modes of development, the consumption of a large amount of resources, and increasing pollutant emissions have created the problems of environmental pollution and ecological degradation in China, and caused significant damage to the natural environment on which human survival and development depends (Cui et al., 2019). The economic losses caused by environmental pollution amount to 54 billion dollars every year, and account for $8 \%$ of China's GDP (World Bank, 1997). Air pollution is the most easily detectable and most widespread problem of ecological and environmental problems. Significant air pollution harms the physical and mental health of residents (Liu et al., 2017). China has been promoting the construction of an ecological civilization since 2012, and since then ecological protection and environmental governance have received 
unprecedented attention. However, the country is still undergoing rapid industrialization and urbanization, and the massive pressure of economic growth on the ecological environment will persist for a long time (Liu et al., 2019). The emissions of sulfur dioxide and other major pollutants were still high in China in 2018, and only 121 of its 338 cities above the prefecture level met the standards of ambient air quality. In the Global Environmental Performance Index Report for 2020, China ranks 137 out of 180 countries in terms of air quality (Wendling et al., 2020). Air pollution is thus a significant problem for the Chinese government. Improving the atmospheric environmental efficiency is an important way to improve the quality of air and to reduce the frequent occurrence of haze (Wang et al., 2017). This research evaluates the urban atmospheric environmental efficiency in China by analyzing the evolution of its spatial pattern and factors influencing it to provide policy recommendations for air pollution control.

The remainder of this paper is arranged as follows: Section 2 provides a literature review and summarizes the contributions of this paper. Section 3 details the data and method used, including the data sources, super-efficiency slacks-based measurement (SBM) model based on unexpected output, spatial autocorrelation, and the Geodetector. Section 4 describes the results including the spatiotemporal evolution and spatial autocorrelation of urban atmospheric environmental efficiency, and factors influencing it in China. Section 5 contains the conclusions of this study and policy recommendations for the government.

\section{Literature review}

"Environmental efficiency" is an instrument for analyzing the impact of economic growth on environmental performance, and was first proposed by the Global Governance and Sustainable Economic Development Forum in 1992 (Song et al., 2013). Its essence is to use fewer resources to yield more economic output and reduce pollution emissions. A growing number of researchers have recognized the importance of assessing environmental efficiency because it can provide designers and public policymakers with quantitative information for performance evaluation, policy analysis, and public communication. All of these benefits render decisions on 
environmental policy more scientific, empirical, and systematic than before. Measuring environmental efficiency in different regions and sectors has become an important direction of research, and the research paradigm has gradually shifted from qualitative to quantitative research (Song et al., 2012).

According to differences of in the researched regions, work on environmental efficiency can be divided into the following three types: (1) Research on the environmental efficiency of the country. Mavi and Mavi (2019) analyzed the environmental efficiency of OECD countries using the Malmquist productivity index, Switzerland was found to have the highest environmental efficiency, whereas Ireland and the USA had continually improved their efficiency. Sun et al. (2020) investigated the environmental efficiency of 104 countries using the Malmquist-Luenberger productivity index, and their results indicate that South Asia had the highest average growth over the period considered whilst East Asia recorded the lowest. Twenty-eight member countries of the European Union were taken as research object in Hermoso-Orzáez et al. (2020)'s research. France, Italy, the Netherlands, Luxembourg, Denmark, Austria, and Sweden were found to generally have high values of environmental efficiency. Due to differences in environmental efficiency among countries, Tateishi et al. (2020) analyzed the influence of institutional quality on environmental efficiency through an analytical framework that is compatible with new institutional economics and production theory. They considered the laws and regulations that have failed to address environmental quality, and concluded that highly developed institutions can play a significant role in improving the situation.

(2) Research on the environmental efficiency of the province. Song et al. (2018, 2019) conducted an empirical analysis of provinces in China using the meta-frontier non-radial angle efficiency model and the RSBM Malmquist-Luenberger index based on the data envelopment analysis (DEA) model. They found that provinces in the east were the most environmentally efficient while those in the central regions were the least. This result had been confirmed in one of their earlier studies, in which the four regions in order of decreasing efficiency were the east, northeast, west, and central parts of China (Song et al., 2013). Li et al. (2020) found that the southeast region of 
China had the highest environmental efficiency, followed by the northeast, southwest, and the northwest. They also found that investment in higher education and the development of information technology can significantly increase regional environmental efficiency.

(3) Research on the environmental efficiency of the city. An et al. (2019) measured the environmental efficiency of cities in the Xiangjiang River Basin in China, and found that Chenzhou and Loudi had the highest environmental efficiencies in 2008-2014, but are smaller than other cities in the area. Sun et al. (2020)'s research reported that the overall environmental efficiency of Chinese cities had increased gradually, but the differences in environmental efficiency between cities had become greater, and the implementation of the high-speed rail had had a significant positive impact on environmental efficiency. An interesting conclusion of Zhang et al. (2019)'s research is that the top three performers in terms of environmental efficiency were Shenzhen, Sanya, and Erdos, whereas Baiyin, Xinzhou, and Liupanshui were the bottom three performers. Lu et al. (2020) found that the average value of overall environmental efficiency of 273 prefecture-level cities in China was only 0.523 , and was high in the eastern region, and low in the central and western regions.

According to research sectors, research on environmental efficiency can be divided into the following three types: (1) Research on the environmental efficiency of the agriculture sector. Drews et al. (2020) considered an increase in energy-corrected milk yield per cow and the amount of energy-corrected milk yield produced per area of agricultural land, accompanied by an improvement in environmental efficiency. Exposito and Velasco (2020) studied the environmental efficiency of the agricultural sector in the use of mineral fertilizers in European countries using the DEA methodology. Belgium-Luxembourg, Denmark, the Netherlands, Sweden, and the United Kingdom registered persistently high values of the estimated indices. Tothmihaly et al. (2019) explored a sustainable increase in cocoa production, i.e., without causing deforestation, and found that increasing environmental efficiency can help realize a win-win-win situation: more cocoa production with more native rainforest plants on fewer hectares. Adenuga et al. (2018) 
assessed the environmental efficiency of dairy farms in the four regions of the island of Ireland using an environmental DEA approach and found regional differences in environmental efficiency, with greater nutrient surpluses in Northern Ireland compared with the three regions in the Republic of Ireland.

(2) Research on the environmental efficiency of the industrial sector. Wang et al. (2020) used a process-level DEA method to evaluate the environmental efficiency of 54 enterprises in the iron and steel industry in China, and found that 12 enterprises had processes with low environmental efficiency whereas 25 had unbalanced environmental performance. Long et al. (2018) investigated the environmental efficiency of 192 thermal power plants using the meta-frontier directional slacks-based measure, and found that the environmental efficiency had increased from 2009 to 2010 and declined in 2011. Sun et al. (2020) explored the effect of market segmentation on the environmental efficiency of electric power industry and claimed that market segmentation hinders technological innovation. Yang and $\mathrm{Li}$ (2021) reported that the relationship between foreign direct investment and industrial environmental efficiency is U-shaped.

(3) Research on the environmental efficiency of the transportation sector. Cui and Jin (2020) studied the environmental efficiency of the airline industry by using the network modified slacks-based measurement model, and found that its environmental efficiency was lower than its production efficiency. Zhu et al. (2020) applied the DEA model to evaluate the environmental efficiency of China's transportation sectors, and showed that some regions had low sustainability-related efficiency. Gong et al. (2019) investigated the environmental efficiency of shipping enterprises and found similar negative environmental impacts.

The research method and paradigm of environmental efficiency have significantly improved through work on different regions and sectors. The environment is a complex system composed of various elements, and can include the atmospheric, water, and soil environments. The prevalent research has studied the efficiency of the environment as a whole, whereas examining the efficiency of a certain element in the environmental system is more valuable. Wang et al. (2016, 
2018) studied the atmospheric environmental efficiency of provinces in China and cities in the Yangtze River Basin. However, no research has examined the atmospheric environmental efficiency of all cities in a country. In this paper, data on 267 cities above the prefecture level between 2001 and 2016 were used to assess their atmospheric environmental efficiency through the super-efficient SBM model based on unexpected output, the factors influencing atmospheric environmental efficiency were simulated using the Geodetector, and policy recommendations to improve atmospheric environmental efficiency are proposed based on the results. The contributions of this paper are as follows: (1) The study of atmospheric environmental efficiency can enrich the research content of environmental efficiency. (2) For the first time, all cities above the prefecture level in China are used as research object to examine urban atmospheric environmental efficiency. This can help explore the spatial law of atmospheric environmental efficiency, and provide policy suggestions for the Chinese government to formulate air pollution prevention and control measures.

3 Data and methods

\subsection{Data sources}

The urban atmospheric environmental efficiency was calculated using input and output indicators. The research by Wang et al. (2020) is used here as reference. The input indicators consisted of capital, labor, and energy, and the output indicators of desirable and undesirable outputs. Capital is expressed using investments in fixed assets, labor using the number of employed persons in urban units, and energy is expressed by the total electricity consumption. Desirable output is expressed using the GDP and undesirable output using the concentration of $\mathrm{PM}_{2.5}$. Table 1 lists the descriptive statistics of all indicators. The concentration of $\mathrm{PM}_{2.5}$ was inverted from the global atmospheric $\mathrm{PM}_{2.5}$ concentration grid data published by the National Aeronautics and Space Administration (NASA) (http://earthdata.nasa.gov), and the other indicators were obtained from the official website of the China National Bureau of Statistics (http://www.stats.gov.cn/tjsj/). 


\begin{tabular}{|c|c|c|c|c|c|c|c|c|}
\hline Indicator & Variable & Unit & $\begin{array}{l}\text { Numb } \\
\text { er of } \\
\text { sampl } \\
\text { es }\end{array}$ & $\begin{array}{c}\text { Average } \\
\text { value }\end{array}$ & Median & $\begin{array}{l}\text { Standard } \\
\text { deviation }\end{array}$ & $\begin{array}{c}\text { Maximum } \\
\text { value }\end{array}$ & $\begin{array}{l}\text { Minimu } \\
\text { m value }\end{array}$ \\
\hline \multirow[t]{3}{*}{$\begin{array}{l}\text { Input } \\
\text { indicator }\end{array}$} & $\begin{array}{l}\text { Investment } \\
\text { in fixed } \\
\text { assets }\end{array}$ & $\begin{array}{c}\text { Ten } \\
\text { thousan } \\
\text { d Yuan }\end{array}$ & 4272 & $\begin{array}{c}4465496.8 \\
4\end{array}$ & $\begin{array}{c}167178 \\
8\end{array}$ & 6419612 & $\begin{array}{c}12756359 \\
3\end{array}$ & 302 \\
\hline & $\begin{array}{c}\text { Number of } \\
\text { employees } \\
\text { in urban } \\
\text { areas }\end{array}$ & $\begin{array}{c}\text { Ten } \\
\text { thousan } \\
\text { d people }\end{array}$ & 4272 & 29.46 & 13.69 & 930471.1 & 791.51 & 0.76 \\
\hline & $\begin{array}{c}\text { Total } \\
\text { electricity } \\
\text { consumption }\end{array}$ & $\begin{array}{c}\text { Ten } \\
\text { thousan } \\
\mathrm{d} \mathrm{kWh}\end{array}$ & 4272 & 685504.30 & 316843 & $\begin{array}{c}1428298 \\
9\end{array}$ & 14860200 & 2248 \\
\hline $\begin{array}{c}\text { Expected } \\
\text { output } \\
\text { indicator }\end{array}$ & GDP & $\begin{array}{c}\text { Ten } \\
\text { thousan } \\
\text { d Yuan }\end{array}$ & 4272 & 8068383 & $\begin{array}{c}264059 \\
1\end{array}$ & $\begin{array}{c}1434933 \\
0\end{array}$ & $\begin{array}{c}28178650 \\
0\end{array}$ & 50594 \\
\hline $\begin{array}{l}\text { Unexpecte } \\
\text { d output } \\
\text { indicator }\end{array}$ & $\begin{array}{c}\mathrm{PM}_{2.5} \\
\text { concentratio } \\
\mathrm{n}\end{array}$ & $\mathrm{mcg} / \mathrm{m}^{3}$ & 4272 & 36.19 & 33.91 & 16.15311 & 90.86 & 4.52 \\
\hline
\end{tabular}

3.2 Methods

\subsubsection{SBM model based on unexpected output}

The inputs of capital, labor, and energy can produce industrial products and economic value, but can also yield undesirables such as air pollutants; this can be considered an undesirable output. The SBM model, proposed by Tone (2001), includes the undesirable output in the production process. As this is in line with the empirical situation, it is widely used to study ecological efficiency (Chen et al., 2020), environmental efficiency (Guo et al., 2018), carbon emission efficiency (Wang and $\mathrm{Du}$, 2019), and energy efficiency (Wang et al., 2019). Compared with the conventional DEA model, the SBM model can solve the problem of input-output relaxation to reflect efficiency that includes undesirable outputs (Liu et al., 2020). The SBM model was used to calculate the urban atmospheric environmental efficiency in China in this study.

Consider a production system with $n$ decision-making units, where each decision-making unit consists of three input-output vectors, and each input-output vector consists of $m$ input units: $S_{1}$ as desirable output, and $S_{2}$ as undesirable output. 
223 The three input-output vectors are expressed as $x \in R^{m}, y^{g}=R^{S_{1}}$, and $y^{b} \in R^{S_{2}}$.

224 The matrices of $X, Y^{g}$, and $Y^{b}$ are as follows:

$$
\begin{aligned}
X & =\left[x_{1}, x_{2}, \cdots, x_{n}\right] \in R^{m \times n} \\
Y^{g} & =\left[y_{1}^{g}, y_{2}^{g}, \cdots, y_{n}^{g}\right] \in R^{s_{1} \times n} \\
Y^{b} & =\left[y_{1}^{b}, y_{2}^{b}, \cdots, y_{n}^{b}\right] \in R^{s_{2} \times n}
\end{aligned}
$$

Suppose $X>0, Y^{g}>0$, and $Y^{b}>0$. The production likelihood is then set as follows:

$$
P=\left\{\left(x, y^{g}, y^{b}\right) \mid x \geq X \theta, y^{g} \geq Y^{g} \theta, y^{b} \leq Y^{b} \theta, \theta \geq 0\right\}
$$

In Eq. (4), the actual desirable output is lower than the frontier ideal desirable output, and the actual undesirable output is higher than the frontier undesirable output. The SBM model with an added decision-making unit $\left(x_{0}, y_{0}^{g}, y_{0}^{b}\right)$ is as follows:

$$
\begin{gathered}
\rho=\min \frac{1-\frac{1}{m} \sum_{i=1}^{m} S_{i}^{-} / x_{i 0}}{1+\frac{1}{S_{1}+S_{2}}\left(\sum_{r=1}^{S_{1}} S_{r}^{g} / y_{r^{0}}^{g}+\sum_{r=1}^{S_{2}} S_{r}^{b} / y_{r^{0}}^{b}\right)}, \\
\text { s.t. }\left\{\begin{array}{c}
x_{0}=X \theta+S^{-} \\
y_{0}^{g}=Y^{g} \theta-S^{g} \\
y_{0}^{b}=Y^{b} \theta-S^{b} \\
S^{-} \geq 0, S^{g} \geq 0, S^{b} \geq 0, \theta \geq 0
\end{array}\right.
\end{gathered}
$$

$S=\left(S^{-}, S^{g}, S^{b}\right)$ expresses the relaxation of the input, desirable output, and undesirable output. The objective function value of $\rho$ is the efficiency of the decision-making unit and its range is $0 \sim 1$. If and only if $\rho=1$, namely $S^{-}=S^{g}=S^{b}=0$, is the given decision-making unit $\left(x_{0}, y_{0}^{g}, y_{0}^{b}\right)$ effective. If $0 \leq \rho<1$, the decision-making unit is inefficient, and the input and output need to be improved. The above model is nonlinear, and can be transformed into a linear model:

$$
\tau=\min t-\frac{1}{m} \sum_{i=1}^{m} \frac{S_{i}^{-}}{x_{i 0}}, \text { s.t. }\left\{\begin{array}{c}
1=t+\frac{1}{S_{1}+S_{2}}\left(\sum_{r=1}^{S_{1}} \frac{S_{r}^{g}}{y_{r 0}^{g}}+\sum_{r=1}^{S_{2}} \frac{S_{r}^{b}}{y_{r 0}^{b}}\right) \\
x_{0} t=X \mu+S^{-} \\
y_{0}^{g} t=Y^{g} \mu-S^{g} \\
y_{0}^{b} t=Y^{b} \mu-S^{b} \\
S^{-} \geq 0, S^{g} \geq 0, S^{b} \geq 0, \mu \geq 0, t>0
\end{array}\right.
$$

To ensure reasonable results of the evaluation, we referred to research by Tone (2001) and used the super efficiency SBM model. It is as follows: 


$$
\begin{gathered}
\rho^{*}=\min \frac{\frac{1}{m} \sum_{i=1}^{m} \frac{\bar{x}_{l}}{x_{i 0}}}{\frac{1}{S_{1}+S_{2}}\left(\sum_{r=1}^{S_{1}} \bar{y}_{r}^{g} / y_{r^{0}}^{g}+\sum_{r=1}^{S_{2}} \bar{y}_{r}^{b} / y_{r^{0}}^{b}\right)}, \\
\text { s.t. }\left\{\begin{array}{c}
\bar{x} \geq \sum_{j=1, \neq k}^{n} \theta_{j} x_{j} \\
\bar{y}^{g} \leq \sum_{j=1, \neq k}^{n} \theta_{j} y_{j}^{g} \\
\bar{y}^{b} \geq \sum_{j=1, \neq k}^{n} \theta_{j} y_{j}^{b} \\
\bar{x} \geq x_{0}, \bar{y}^{g} \leq y_{0}^{g}, \bar{y}^{b} \geq y_{0}^{b}, \bar{y}^{g} \geq 0, \theta \geq 0
\end{array}\right.
\end{gathered}
$$

237 The objective function value of $\rho^{*}$ expresses the efficiency of the decision-making 238 unit, and the definitions of the other variables are the same as in Eq. (6). The above 239 models are based on the assumption of a constant scale.

\subsubsection{Spatial autocorrelation}

The global Moran's index (Moran's $I$ ) was used to test the global spatial autocorrelation of atmospheric environmental efficiency. If Moran's $I$ is greater than 0 , the research object is positively spatially autocorrelated, and the larger the value is, the stronger is the spatial agglomeration of the atmospheric environmental efficiency between cities. If Moran's $I$ is less than 0 , the research object is negatively spatially autocorrelated, and smaller value indicates a stronger spatial dispersion of the atmospheric environmental efficiency between cities. The formula for the global Moran's $I$ is as follows:

$$
I=\frac{\sum_{i=1}^{n} \sum_{j=1}^{n} W_{i j}\left(x_{i}-\bar{x}\right)\left(x_{j}-\bar{x}\right)}{S^{2} \sum_{i=1}^{n} \sum_{j=1}^{n} W_{i j}}
$$

$$
S=\frac{1}{n} \sum_{i=1}^{n}\left(x_{i}-\bar{x}\right)^{2}
$$

$250 n$ expresses the number of cities, $x i$ and $y j$ are the atmospheric environmental 251 efficiency of cities $i$ and $j$, respectively, $\bar{x}$ expresses the average value of the 252 atmospheric environmental efficiency of all cities, and Wij expresses the spatial 253 weight matrix of cities $i$ and $j$. If there is a public boundary between cities, then $W i j=$ 2541 ; if not, then $W_{i j}=0$. To test the significance of the global Moran's $I$, the 
standardized statistic of Moran's $I$ is defined as follows:

$$
Z(I)=\frac{[1-E(I)]}{\sqrt{\operatorname{Var}(I)}}
$$

$Z(I)$ can measure the significance of the global Moran's $I, E(I)$ expresses the mathematical expectation of $I$, and $\operatorname{Var}(I)$ expresses its variance.

The local Moran's $I$ of atmospheric environmental efficiency was tested using local spatial autocorrelation, and is defined as follows:

$$
I_{i}=\frac{\sum_{i=1}^{n} \sum_{j=1}^{n} W_{i j}\left(x_{i}-\bar{x}\right)\left(x_{j}-\bar{x}\right)}{S^{2}}
$$

The significance of the local Moran's $I$ was tested using $Z(I)$, and Eq. (10) was used to calculate it. Cities whose significance reached a certain threshold $(p=0.05)$ were divided into four types. If Moran's $I$ was significantly positive and $Z(I)>0$, the city was called a "high-high"-type city, and this indicated that the atmospheric environmental efficiency of this city and contiguous cities was high. This type can be called a "hot spot." If Moran's $I$ was significantly positive and $Z(I)<0$, the given city was termed a "low-low"-type city, and this indicated that the atmospheric environmental efficiency of this and contiguous cities was low; this type can be termed a "cold spot." If Moran's $I$ was significantly negative and $Z(I)>0$, the given city was termed a "high-low" city, which indicated that cities with high atmospheric environmental efficiency were surrounded by those with low efficiency. If Moran's $I$ was significantly negative and $Z(I)<0$, the city was termed a "low-high" city, and this indicated that cities with low atmospheric environmental efficiency were surrounded by those with high efficiency.

\subsubsection{Geodetector}

The Geodetector is a statistical method to explore the spatial heterogeneity of a research object and reveal its factors influencing it. This method makes no assumption of linearity, but has an elegant form and a clear physical meaning (Wang et al., 2010). The core idea of the Geodetector method is as follows: Suppose the study region is divided into several sub-regions. If the sum of the variance of the sub-region is smaller than the total variance of the region, some spatial differentiation exists. If the spatial distribution of the two variables tends to be consistent, there is a statistical 
correlation between them (Wang and $\mathrm{Xu}, 2010$ ). The statistic $q$ can be used to measure the spatial differentiation, explore explanatory factors, and analyze the interaction between variables. It has been widely used to examine factors influencing the atmospheric environment (Zhou et al., 2019; Huang et al., 2020). The factors influencing atmospheric environmental efficiency were measured using this method. The model can be described as follows:

$$
P_{D, H}=1-\frac{1}{n \sigma_{H}^{2}} \sum_{i=1}^{n} n_{D, i} \sigma \frac{2}{H_{D, J}}
$$

$P_{D, H}$ expresses the explanatory power of the factors influencing urban atmospheric environmental efficiency, $D$ is the factor influencing atmospheric environmental efficiency, $n$ and $\sigma^{2}$ are number and variance of the samples, respectively, $m$ expresses the number of categories of a given influential factor, and $n_{D, i}$ expresses the number of indices $D$ in sample $i$. The range of values of $P_{D, H}$ is $0 \sim 1$; the larger the value is, the stronger the explanatory power of the factor influencing atmospheric environmental efficiency is.

4 Results

\subsection{Spatiotemporal evolution of urban atmospheric environmental efficiency}

The results of urban atmospheric environmental efficiency between 2001 and 2016 are mapped in Fig. 1. Of the 267 cities studied, the atmospheric environmental efficiency of 217 showed a trend of gradual improvement, accounting for $81 \%$ of the total. The atmospheric environmental efficiency of 50 cities showed a gradual downward trend, and these are Shenyang, Dalian, Anshan, Changchun, Harbin, Jixi, Shuangyashan, Heihe, Shanghai, Wuxi, Hangzhou, Ningbo, Wenzhou, Taizhou (in Zhejiang province), Fuyang, Xuancheng, Chifeng, Chengde, Jincheng, Fuzhou, Xiamen, Ningde, Nanchang, Pingxiang, Ganzhou, Jinan, Zibo, Weifang, Binzhou, Jingmen, Xiaogan, Suizhou, Changsha, Yueyang, Jiangmen, Zhanjiang, Dongguan, Jieyang, Hezhou, Guangan, Bazhong, Anshun, Yuxi, Zhaotong, Xi'an, Xianyang, Pingliang, Jiuquan, Urumqi, and Karamay. Interestingly, both economically developed and underdeveloped cities compose this type. Fuzhou (in Jiangxi province), Suihua, Karamay, Dongguan, Dongguan, Dongguan, Ordos, Meizhou (in Guangdong 
province), Yichang, Dongguan, Ordos, Ordos, Tongliao, Baotou, and Daqing had the highest atmospheric environmental efficiency from 2001-2016, in decreasing order of

312 efficiency. Lvliang, Lvliang, Jiayuguan, Jiaozuo, Jiaozuo, Jincheng, Jiaozuo, Jiaozuo,

313 Datong, Jiaozuo, Jiaozuo, Heihe, Heihe, Heihe, Heihe, and Heihe had the lowest atmospheric environmental efficiency from 2001-2016. Fig. 2 shows the trend of evolution of the average value of urban atmospheric environmental efficiency in the entire country and the four regions. The average urban atmospheric environmental

317 efficiency in China showed a "wavy" upward trend, with peaks in 2006 and 2010. A comparison of the values of the four regions shows that the urban atmospheric environmental efficiency in Eastern China was the highest and that in Western China was the lowest.
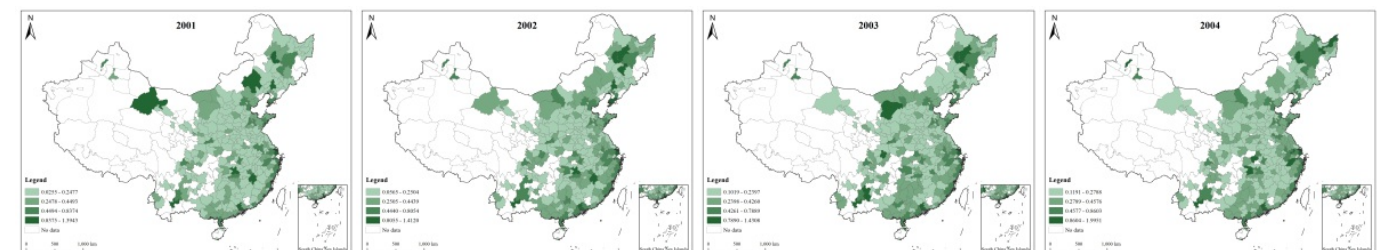

322
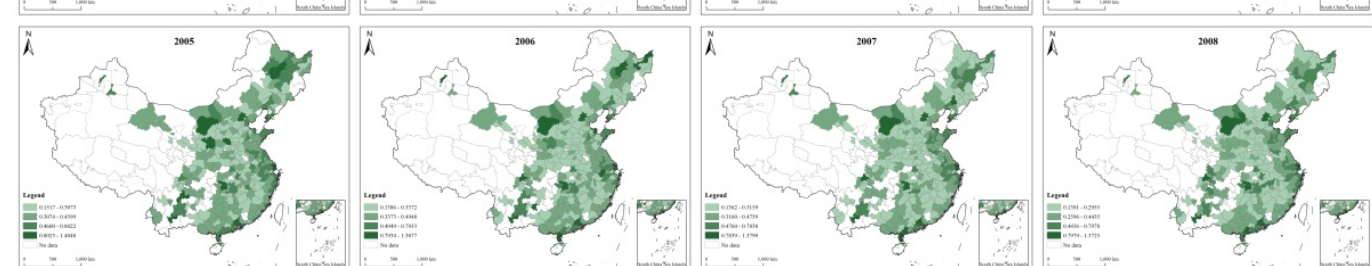

323

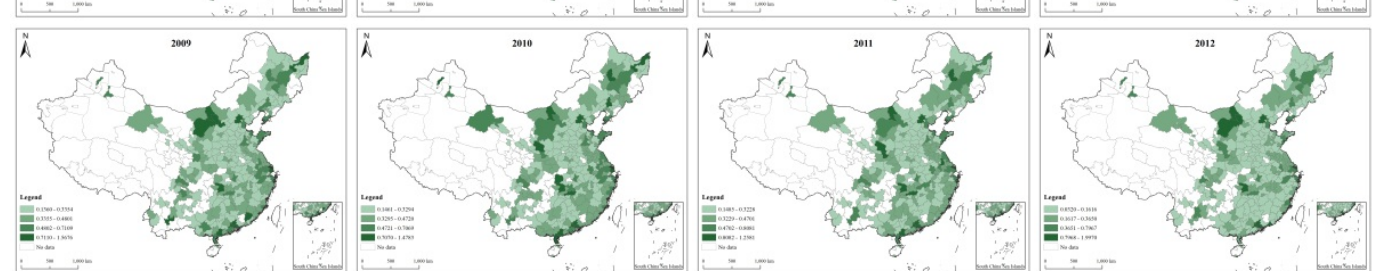

Fig. 1. The results of urban atmospheric environmental efficiency between 2001 and 2016 


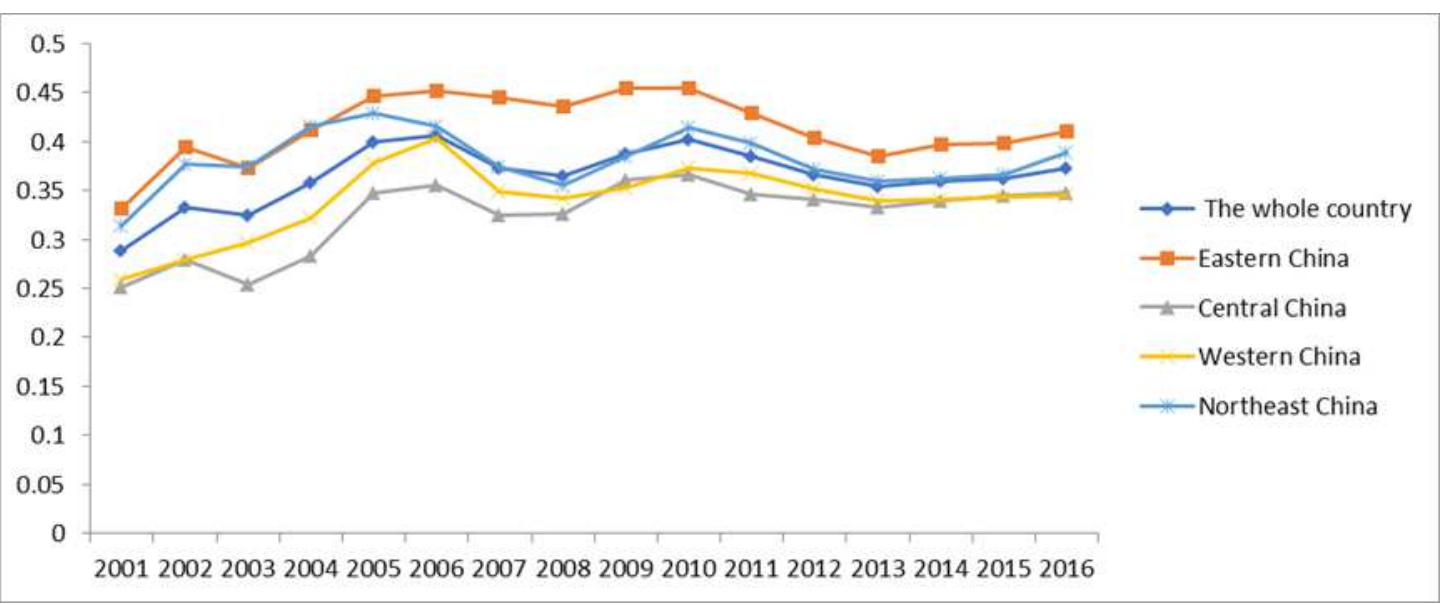

Fig. 2. The trend of evolution of the average value of urban atmospheric environmental efficiency in China and its four regions

4.2 Spatial autocorrelation of urban atmospheric environmental efficiency

\subsubsection{Global spatial autocorrelation}

The global spatial autocorrelation of urban atmospheric environmental efficiency between 2001 and 2016 was tested using ArcGIS 10.2, and the results are shown in Table 2. All values of the global Moran's $I$ were positive, and passed the $1 \%$ significance test. This explains the similar characteristics of spatial agglomeration of urban atmospheric environmental efficiency in China. The global Moran's I exhibited a trend of first rising and then decreasing, where the point of inflection appeared in 2007.

Table 2 Results of global spatial autocorrelation of urban atmospheric environmental efficiency between 2001 and 2016

\begin{tabular}{|c|c|c|c|}
\hline Year & Moran's $I$ & $Z$ & $P$ value \\
\hline 2001 & 0.129604 & 5.456604 & 0.000000 \\
\hline 2002 & 0.213305 & 8.850678 & 0.000000 \\
\hline 2003 & 0.231225 & 9.595016 & 0.000000 \\
\hline 2004 & 0.224345 & 9.407326 & 0.000000 \\
\hline 2005 & 0.208459 & 8.664341 & 0.000000 \\
\hline 2006 & 0.213767 & 8.870790 & 0.000000 \\
\hline 2007 & 0.245834 & 10.212385 & 0.000000 \\
\hline 2008 & 0.222931 & 9.293746 & 0.000000 \\
\hline 2009 & 0.204906 & 8.551084 & 0.000000 \\
\hline 2010 & 0.191744 & 7.982884 & 0.000000 \\
\hline 2011 & 0.206783 & 8.604095 & 0.000000 \\
\hline 2012 & 0.186318 & 7.947985 & 0.000000 \\
\hline
\end{tabular}




\begin{tabular}{|l|l|l|l|}
\hline 2013 & 0.159727 & 6.712538 & 0.000000 \\
\hline 2014 & 0.127890 & 5.395022 & 0.000000 \\
\hline 2015 & 0.154033 & 6.470255 & 0.000000 \\
\hline 2016 & 0.135438 & 5.705741 & 0.000000 \\
\hline
\end{tabular}

4.2.2 Local spatial autocorrelation

The results of the local spatial autocorrelation of urban atmospheric environmental efficiency between 2001 and 2016 are shown in Fig. 3. The given distribution can be divided into four types: that is, high-high, low-low, high-low, and low-high. The high-high type featured the situation where the atmospheric environmental efficiency in a particular city and adjacent cities were high. This type was located in the Yangtze River Delta urban agglomeration, Pearl River Delta urban agglomeration, Harbin Changchun urban agglomeration, Central Yunnan urban agglomeration, and Hohhot Baotou Erdos Yulin urban agglomeration. The low-low type featured the situation where the atmospheric environmental efficiency in a particular city and the adjacent cities were low. This type was widely distributed in Shanxi, Hebei, Henan, and Gansu province. The high-low type represented a situation where the atmospheric environmental efficiency in one city was significantly higher than that in adjacent cities, and the spatial pattern was high in the middle and low in the peripheries. The low-high type depicted a scenarios where the atmospheric environmental efficiency in a particular city was significantly lower than that of adjacent cities, and the spatial pattern was low in the middle and high in the peripheries. The numbers of cities of high-high type and low-low type were significant greater than those of the other two types.

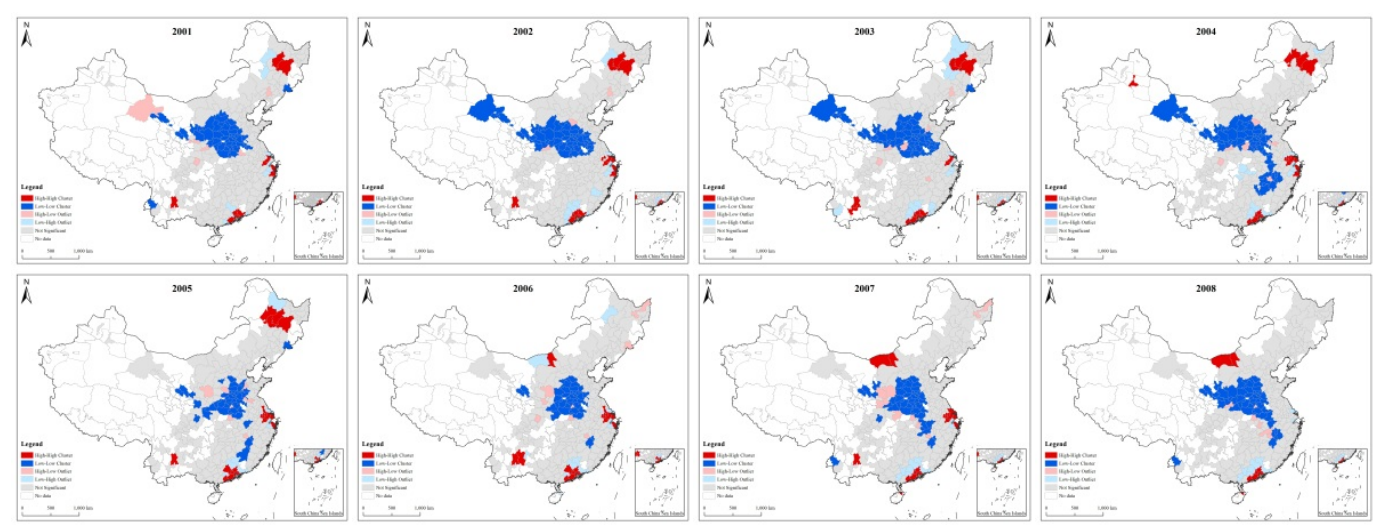




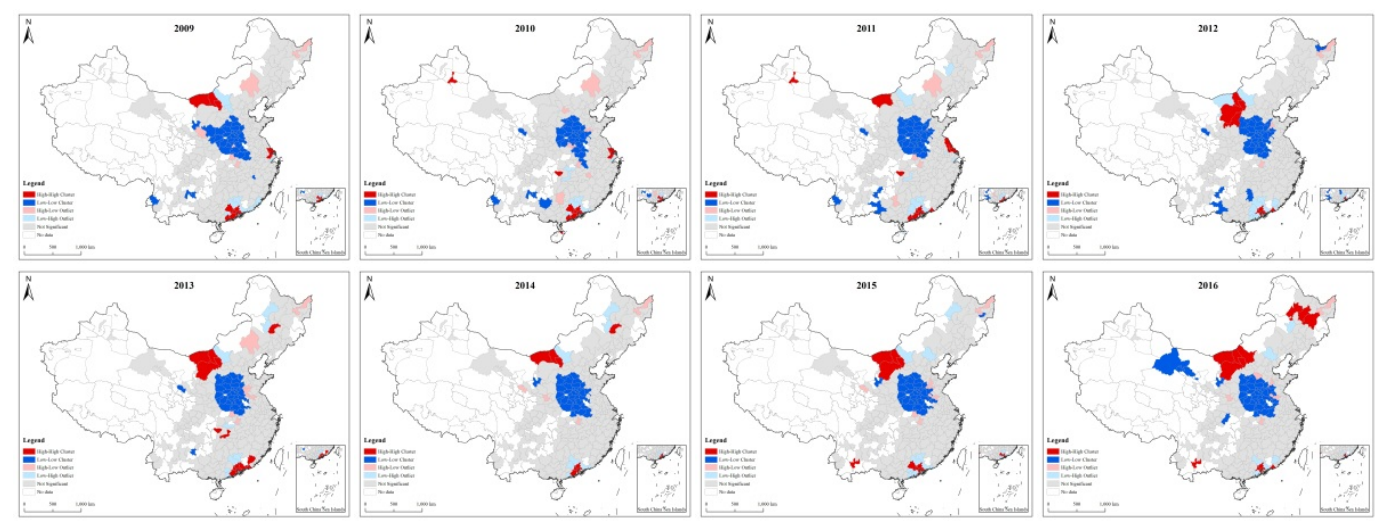

362

363

Fig. 3. The results of local spatial autocorrelation of urban atmospheric environmental efficiency between 2001

$$
\text { and } 2016
$$

\subsection{Factors influencing urban atmospheric environmental efficiency}

Shao et al. (2019), Lin and Tan (2019), and Chen and Chen (2018)'s work was used as reference to analyze the effects of population density, urbanization, industrialization, science and technology, opening to the world, social welfare, and environmental regulation on urban atmospheric environmental efficiency. Population density reports the effect of the effect of population agglomeration on urban atmospheric environmental efficiency. Urbanization is reflected using land urbanization to distinguish it from population density, and expressed using the ratio of land for urban construction to all land in municipal areas. Industrialization is expressed using the added value of the secondary industry. Science and technology is expressed using the ratio of expenditure of science and technology to total expenditure, opening to the world is expressed using the amount of foreign capital utilized, social welfare is expressed using the average wage of employees, and environmental regulation is expressed using the comprehensive rate of utilization of industrial solid waste. The results of the geographical detection of urban atmospheric environmental efficiency between 2001 and 2016 are shown in Table 3.

Table 3 Results of geographical detection for urban atmospheric environmental efficiency between 2001 and 2016

\begin{tabular}{|c|c|c|c|c|c|c|c|}
\hline Year & $\begin{array}{c}\text { Population } \\
\text { density }\end{array}$ & Urbanization & Industrialization & $\begin{array}{c}\text { Science } \\
\text { and } \\
\text { technology }\end{array}$ & $\begin{array}{c}\text { Opening } \\
\text { to the } \\
\text { world }\end{array}$ & $\begin{array}{c}\text { Social } \\
\text { welfare }\end{array}$ & $\begin{array}{c}\text { Environmental } \\
\text { regulation }\end{array}$ \\
\hline 2001 & 0.1246 & 0.0111 & 0.1143 & 0.2630 & 0.0033 & 0.0028 & 0.0050 \\
\hline 2002 & 0.1341 & 0.0188 & $0.1398^{* *}$ & 0.2762 & 0.0029 & 0.0023 & 0.0072 \\
\hline 2003 & 0.1182 & 0.0404 & $0.1553^{* *}$ & 0.2560 & 0.0029 & 0.0023 & 0.0078 \\
\hline 2004 & 0.1182 & 0.0404 & $0.1425^{* *}$ & 0.3042 & 0.0023 & $0.0025^{*}$ & 0.0078 \\
\hline 2005 & 0.1523 & 0.0466 & $0.1503^{* *}$ & 0.3617 & 0.0050 & $0.0024^{* *}$ & 0.0088 \\
\hline
\end{tabular}




\begin{tabular}{|c|c|c|c|c|c|c|c|}
\hline 2006 & 0.1522 & 0.0466 & 0.1236 & 0.3617 & 0.0040 & 0.0024 & 0.0088 \\
\hline 2007 & 0.1645 & 0.0346 & 0.1206 & 0.3426 & 0.0044 & 0.0021 & 0.0080 \\
\hline 2008 & 0.1834 & 0.0264 & $0.1318^{* *}$ & 0.3511 & 0.0039 & $0.0029 * *$ & 0.0070 \\
\hline 2009 & 0.1801 & 0.0313 & $0.1459^{* *}$ & 0.3779 & 0.0048 & $0.0020^{* *}$ & 0.0074 \\
\hline 2010 & $0.1326^{*}$ & 0.0555 & 0.1971 & 0.3998 & 0.0052 & 0.0015 & 0.0071 \\
\hline 2011 & 0.1572 & 0.0532 & 0.1918 & 0.4405 & 0.0033 & 0.0014 & 0.0080 \\
\hline 2012 & 0.1322 & 0.0508 & 0.2025 & 0.4676 & 0.0039 & 0.0014 & 0.0088 \\
\hline 2013 & 0.1502 & 0.0563 & 0.2268 & 0.4738 & 0.0033 & 0.0013 & 0.0088 \\
\hline 2014 & 0.1890 & 0.0470 & 0.2178 & 0.4715 & 0.0041 & $0.0019 * *$ & 0.0089 \\
\hline 2015 & 0.1652 & 0.0456 & 0.2256 & 0.4884 & 0.0045 & 0.0010 & 0.0083 \\
\hline 2016 & 0.2446 & 0.0471 & 0.2598 & 0.4884 & 0.0048 & 0.0018 & 0.0081 \\
\hline
\end{tabular}

Note: *, and ** represent significance at levels of $10 \%$ and $5 \%$, respectively; other values are significant at the $1 \%$ level.

The intensities of contribution of different factors on urban atmospheric environmental efficiency show that population density, industrialization, and science and technology had clearly greater effects than the other factors, and exhibited a trend of rising. These, then, are the main factors influencing urban atmospheric environmental efficiency.

The population density of most cities is on the rise in China, which means that the degree of population agglomeration is gradually increasing. The scale effect of population agglomeration on air pollution is greater than the agglomeration effect, and increasing population density is the fundamental reason for the decline in air quality (Shao et al., 2016; Wang 2015). On the one hand, the increase in urban population and increases in levels of consumption lead to an increase of pollutants in the environment; on the other, the production capacity increases to meet the basic living needs of the increasing population and economic production increases the emission of air pollutants. The increase in population density thus leads to an increase in air pollutants, which are an factor influencing urban atmospheric environmental efficiency.

After the Reform and Opening Up, China began to industrialize. In the $21^{\text {st }}$ century, its industrialization process has continued to accelerate. However, industrialization boosts the rapid development of economy while creating the problem of resource consumption and environmental pollution. The main pollutant emissions 
403 in China are still the highest in the world, with industrial pollution emissions accounting for more than $70 \%$ of total national pollution. Cities are the main sources of industrial pollution (Li et al., 2019; Yang et al., 2020). The industrialization of some cities in China is characterized by high input, low output, and high pollution. Because of this, the government has begun emphasizing the quality of industrial development since 2013 to protect the ecological environment (Shi and Li, 2019). Industrialization with extensive features is an important factor affecting urban atmospheric environmental efficiency.

Science and technology is an important indicator of comprehensive national strength. Science and technology has proven to be have dual effects on the environment. On the one hand, technological progress can improve the efficiency of utilization of resources and the environment to reduce emissions in the production process (Li et al., 2020). On the other hand, it may expand the scale of production and increase the emission of environmental pollutants (Shao et al., 2013). Given urban development in China, improving the level of science and technology can help cities reduce the cost of production, improve production efficiency, and encourage them to rely on new technologies to reduce air pollutant emissions. This will improve urban atmospheric environmental efficiency.

\section{Conclusions and policy recommendations}

\subsection{Conclusions}

The results of this study show that the atmospheric environmental efficiency of most cities in China is increasing, the average value of urban atmospheric environmental efficiency in the country exhibits a wavy upward trend, and the average urban atmospheric environmental efficiency in Eastern China is the highest while that in Western China is the lowest.

The spatial autocorrelation analysis of urban atmospheric environmental efficiency shows that it exhibits the characteristic of global spatial autocorrelation each year, whereas its local spatial autocorrelation can be divided into four types: that is, high-high, low-low, high-low, and low-high scenarios. The high-high and low-low scenarios are the main representatives of urban atmospheric environmental 
efficiency in terms of local spatial autocorrelation. The high-high type scenarios is concentrated in the Yangtze River Delta urban agglomeration, Pearl River Delta urban agglomeration, Harbin Changchun urban agglomeration, Central Yunnan urban agglomeration, and Hohhot Baotou Erdos Yulin urban agglomeration. The low-low type scenarios are located in Shanxi, Hebei, Henan, and Gansu province.

The geographical detection of urban atmospheric environmental efficiency showed that population density, industrialization, and science and technology are the main factors influencing urban atmospheric environmental efficiency.

\subsection{Policy recommendations}

First, urban atmospheric environmental efficiency is the result of the comprehensive effects of economic growth and air pollution. To improve it, the government needs to change the mode of economic growth, from traditional extensive growth to intensive growth, and improve the rate of utilization of resources and energy while reducing the emission of pollutants. Second, the urban atmospheric environmental efficiency in different regions showed significant differences. Thus, all regions need to strengthen cooperation and exchange, eliminate fragmentation and local protectionism, and share energy-saving and emission reduction technologies. Third, in view of the effect of population density on urban atmospheric environmental efficiency, new urbanization and smart growth modes are necessary for cities. Chinese cities need to change their model of expansion, reasonably plan the population size and density, and carry out compact and intensive development. Fourth, the problem of air pollution caused by industrial growth is difficult to avoid in a short time, and the government needs to consider the industrial ecological modes and cleaner production modes from a long-term perspective. Sixth, the government needs to give full play to the role of technological progress, which requires the promotion of advanced air pollution prevention technology and equipment in practice.

\section{Disclosure statement}

The authors have no potential conflicts of interest. 


\section{Fundings}

This work was supported by the National Natural Science Foundation of China (Grant No. 72004124), Key Research and Development Plan of Shandong Province (Grant No. 2020RKB01112), Philosophy and Social Science Project of Jinan City (Grant No. JNSK20C13), and Key Project of Social Science Planning of Shandong Province (Grant No. 20BJJJ06).

\section{References}

An Q., Wu Q., Li J., Xiong B., Chen X., 2019. Environmental efficiency evaluation for Xiangjiang River basin cities based on an improved SBM model and Global Malmquist index. Energy Economics. 81, 95-103. DOI 10.1016/j.eneco.2019.03.022

Chen S., Chen D., 2018. Air pollution, government regulations and high-quality economic development. Economic Research Journal. 53 (2), 20-34. DOI CNKI:SUN:JJYJ.0.2018-02-003

Cui Q., Jin Z., 2020. Airline environmental efficiency measures considering negative data: An application of a modified network Modified Slacks-based measure model. Energy. 207, 118221. DOI 10.1016/j.energy.2020.118221

Cui Q., Jin Z., 2020. Airline environmental efficiency measures considering negative data: An application of a modified network Modified Slacks-based measure model. Energy. 207, 118221. DOI 10.1016/j.energy.2020.118221

Cui X., Fang C., Liu H., Liu X., 2019. Assessing sustainability of urbanization by a coordinated development index for an Urbanization-Resources-Environment complex system: A case study of Jing-Jin-Ji region, China. Ecological Indicators. 96, 383-391. DOI 10.1016/j.ecolind.2018.09.009

Drews J., Czycholl I., Krieter J., 2020. A life cycle assessment study of dairy farms in northern Germany: The influence of performance parameters on environmental efficiency. Journal of Environmental Management. 273, 111127. DOI 10.1016/j.jenvman.2020.111127

Exposito A., Velasco F., 2020. Exploring environmental efficiency of the European 
agricultural sector in the use of mineral fertilizers. Journal of Cleaner Production. 253, 119971. DOI 10.1016/j.jclepro.2020.119971

Gong X., Wu X., Luo M., 2019. Company performance and environmental efficiency: A case study for shipping enterprises. Transport Policy. 82, 96-106. DOI 10.1016/j.tranpol.2018.04.008

Guo S., Tong M., Guo J., Han Y., 2018. Measurement and influencing factors of inter-provincial real environmental efficiency based on three-stage DEA model. China Population, Resources and Environment. 28, 106-116. DOI 10.12062/cpre. 20170917

Hermoso-Orzáez M. J., García-Alguacil M., Terrados-Cepeda J., Brito P., 2020. Measurement of environmental efficiency in the countries of the European Union with the enhanced data envelopment analysis method (DEA) during the period 2005-2012. Environmental Science and Pollution Research. 27, 15691-15715. DOI 10.1007/s11356-020-08029-3

Huang C., Liu K., Zhou L., 2020. Spatio-temporal trends and influencing factors of PM2.5 concentrations in urban agglomerations in China between 2000 and 2016. Environmental Science and Pollution Research. DOI $10.1007 / \mathrm{s} 11356-020-11357-\mathrm{Z}$

Li H., Zhao X., Wang W., Xue B., 2019. Spatio-temporal differentiation and influencing factors of urban industrial pollution in China based on multi-scales: 2005-2015. Geographical Research. 38 (8), 1993-2007. DOI $10.11821 /$ dlyj020180480

Li J., Ma J., Wei W., 2020. Study on regional differences of energy carbon emission efficiency in eight economic areas of China. The Journal of Quantitative \& Technical Economics. 37 (6),109-129. DOI 10.13653/j.cnki.jqte.2020.06.006

Li Y., Zhang Qi., Wang L., Liang L., 2020. Regional environmental efficiency in China: An empirical analysis based on entropy weight method and non-parametric models. Journal of Cleaner Production. 276, 124147. DOI 10.1016/j.jclepro.2020.124147

Lin B., Tan R., 2019. Economic agglomeration and green economy efficiency in 
China. Economic Research Journal. 54 (2), 119-132. DOI CNKI:SUN:JJYJ.0.2019-02-009

Liu H., Fang C., Zhang X., Wang Z., Bao C., Li F., 2017. The effect of natural and anthropogenic factors on haze pollution in Chinese cities: A spatial econometrics approach. Journal of Cleaner Production. 165, 323-333. DOI 10.1016/j.jclepro.2017.07.127

Liu K, Xue M., Peng M., Wang C., 2020. Impact of spatial structure of urban agglomeration on carbon emissions: An analysis of the Shandong Peninsula, China. Technological Forecasting and Social Change. 161, 120313. DOI 10.1016/j.techfore.2020.120313

Liu K., Wu Y., Tao Y., Wang C., 2019. The influence of ecological civilization construction to carbon emission intensity in China's provinces. China population, resources and environment. 29, 50-56. DOI 10.12062/cpre.20190301

Liu X., Guo P., Yue X., Qi X., Guo S., Zhou X., 2020. Measuring metabolic efficiency of the Beijing-Tianjin-Hebei urban agglomeration: A slacks-based measures method. Resources Policy. DOI 10.1016/j.resourpol.2020.101928

Long X., Wu C., Zhang J., Zhang J., 2018. Environmental efficiency for 192 thermal power plants in the Yangtze River Delta considering heterogeneity: A metafrontier directional slacks-based measure approach. Renewable and Sustainable Energy Reviews. 82, 3962-3971. DOI 10.1016/j.rser.2017.10.077

Lu J., Li B., Li H., Zhang X., 2020. Characteristics, exchange experience, and environmental efficiency of mayors: Evidence from 273 prefecture-level cities in China. Journal of Environmental Management. 255, 109916. DOI 10.1016/j.jenvman.2019.109916

Mavi N. K., Mavi R. K., 2019. Energy and environmental efficiency of OECD countries in the context of the circular economy: Common weight analysis for malmquist productivity index. Journal of Environmental Management. 247, 651-661. DOI 10.1016/j.jenvman.2019.06.069

Ministry of Ecology and Environment of China, 2019. Bulletin on the state of China's ecological environment in 2018. 

http://www.mee.gov.cn/hjzl/zghjzkgb/lnzghjzkgb/201905/P02019061958763263 0618.pdf

National Bureau of Statistics of China, 2004-2018. China City Statistical Yearbook. Beijing: China Statistics Press.

National Bureau of Statistics of China, 2020. China Statistical Yearbook. Beijing: China Statistics Press.

Shao S., Li X., Cao J., 2019. Urbanization promotion and haze pollution governance in China. Economic Research Journal. 64 (2), 148-165. DOI CNKI:SUN:JJYJ.0.2019-02-011

Shao S., Li X., Cao J., Yang L., 2016. China's economic policy choices for governing smog pollution based on spatial spillover effects. Economic Research Journal. 51 (9), 73-88. DOI CNKI:SUN:JJYJ.0.2016-09-007

Shao S., Yang L., Huang T., 2013. Theoretical model and experience from China of energy rebound effect. Economic Research Journal. 48 (2), 96-109. DOI CNKI:SUN:JJYJ.0.2013-02-009

Shi D., Li P., 2019. Quality evolution and assessment of China's industry over the past seven decades. China Industrial Economics. 35 (9), 5-23. DOI 10.19581/j.cnki.ciejournal.2019.09.001

Song M., An Q., Zhang W., Wang Z., Wu J., 2012. Environmental efficiency evaluation based on data envelopment analysis: A review. Renewable and Sustainable Energy Reviews. 16, 4465-4469. DOI 10.1016/j.rser.2012.04.052

Song M., Peng J., Wang J., Zhao J., 2018. Environmental efficiency and economic growth of China: A Ray slack-based model analysis. European Journal of Operational Research. 269, 51-63. DOI 10.1016/j.ejor.2017.03.073

Song M., Song Y., Yu H., Wang Z., 2013. Calculation of China's environmental efficiency and relevant hierarchical cluster analysis from the perspective of regional differences. Mathematical and Computer Modelling. 58, 1084-1094. DOI 10.1016/j.mcm.2012.04.003

Song M., Wang S., Lei L., Zhou L., 2019. Environmental efficiency and policy change in China: A new meta-frontier non-radial angle efficiency evaluation 
approach. Process Safety and Environmental Protection. 121, 281-289. DOI 10.1016/j.psep.2018.10.023

Song M., Zhang L., An Q X., Wang Z., Li Z., 2013. Statistical analysis and combination forecasting of environmental efficiency and its influential factors since China entered the WTO: 2002-2010-2012. Journal of Cleaner Production. 42, 42-51. DOI 10.1016/j.jclepro.2012.11.010

Sun H., Kporsu A. K., Taghizadeh-Hesary F., Edziah B. K., 2020. Estimating environmental efficiency and convergence: 1980 to 2016. Energy. 208, 118224. DOI 10.1016/j.energy.2020.118224

Sun X., Yan S., Liu T., Wu J., 2020. High-speed rail development and urban environmental efficiency in China: A city-level examination. Transportation Research Part D. 86, 102456. DOI 10.1016/j.trd.2020.102456

Sun X., Zhou X., Chen Z., Yang Y., 2020. Environmental efficiency of electric power industry, market segmentation and technological innovation: Empirical evidence from China. Science of the Total Environment. 706, 135749. DOI 10.1016/j.scitotenv.2019.135749

Tateishi H. R., Bragagnolo C., Faria R. N., 2020. Economic and environmental efficiencies of greenhouse gases' emissions under institutional influence. Technological Forecasting and Social Change. 161, 120321. DOI 10.1016/j.techfore.2020.120321

Tone K., 2001. A slacks-based measure of efficiency in data envelopment analysis. European Journal of Operational Research. 130, 498-509. DOI 10.1016/S0377-2217(99)00407-5

Tothmihaly A., Ingram V., Cramon-Taubadel S., How can the environmental efficiency of Indonesian cocoa farms be increased? Ecological Economics. 158, 134-145. DOI 10.1016/j.ecolecon.2019.01.004

Wang J., Li X., Christakos G., Liao Y., Zhang T., Gu X., Zheng X., 2010. Geographical detectors-based health risk assessment and its application in the neural tube defects study of the Heshun region, China. International Journal of Geographical Information Science. 24 (1), 107-127. DOI 


\section{$10.1080 / 13658810802443457$}

Wang J., Wang S., Li S., Cai Q., Gao S., 2019. Evaluating the energy-environment efficiency and its determinants in Guangdong using aslack-based measure with environmental undesirable outputs and panel data model. Science of the Total Environment. 663, 878-888. DOI 10.1016/j.scitotenv.2019.01.413

Wang K., Meng X., Yang B., Cheng Y., 2016. Study on the atmospheric environmental performance of China's regional economic development. The Journal of Quantitative and Technical Economics. 33, 59-76. DOI 10.13653/j.cnki.jqte.2016.11.004

Wang K., Meng X., Yang B., Cheng Y., 2017. Study on the heterogeneity, dynamic evolution and cause recognition of China's regional air environmental efficiency. Statistics and Information Forum. 32, 55-63. DOI 1007-3116(2017)06-0055-09

Wang K., Shi L., Liu L., Du Y., Meng X., Yang B., 2018. Study on the temporal-spatial heterogeneity and driving factors of air environmental efficiency for Yangtze River Economic Zone. Resources and Environment in the Yangtze Basin. 27, 453-462. DOI 10.11870 /cjlyzyyhj201803001

Wang S., Gao S., Huang Y., Shi C., 2020. Spatio-temporal evolution and trend prediction of urban carbon emission performance in China based on super-efficiency SBM model. Acta Geographica Sinica. 75, 1316-1330. DOI $10.11821 / \mathrm{dlxb} 202006016$

Wang X., Xie G., Yue S., 2015. Impact of economic growth and population aggregation on urban environmental quality and its regional differentiation: A case study of 74 cities implemented the new standard for air quality during the $\begin{array}{llllll}\text { first stage. Economic Geography. } 35 & \text { (2), 71-76. DOI }\end{array}$ 10.15957/j.cnki.jjd1.2015.02.010

Wang Y., Wen Z., Cao X., Zheng Z., Xu J., 2020. Environmental efficiency evaluation of China's iron and steel industry: A process-level data envelopment analysis. Science of the Total Environment. 707, 135903. DOI 10.1016/j.scitotenv.2019.135903

Wang Z., Du Y., 2019. Spatial-temporal differences and influencing factors of carbon 

emission efficiency in Hunan province based on SBM-DEA model. Scientia Geographica Sinica. 39, 797-806. DOI 10.13249/j.cnki.sgs.2019.05.011

Wendling Z., Emerson J., Sherbinin A., Esty D., 2020. Environmental Performance Index 2020. New Haven CT: Yale Center for Environmental Law \& Policy.

World Bank, 1997. China 2020: Development challenges in the new century. London: Oxford University Press.

Yang M., Yan X., Li Q., 2020. Study on the impact of environmental regulation on the efficiency of industrial pollution control in China. China Population, Resources and Environment. 30 (9), 54-61. DOI 10.12062/cpre.20200308

Yang X., Li C., 2019. Industrial environmental efficiency, foreign direct investment and export--Evidence from 30 provinces in China. Journal of Cleaner Production. 212, 1490-1498. DOI 10.1016/j.jclepro.2018.12.156

Zhang Y., Shen L., Shuai C., Bian J., Zhu M., Tan Y., Ye G., 2019. How is the environmental efficiency in the process of dramatic economic development in the Chinese cities? Ecological Indicators. 98, 349-362. DOI 10.1016/j.ecolind.2018.11.006

Zhou C., Shi C., Wang S., Zhang G., 2018. Estimation of eco-efficiency and its influencing factors in Guangdong province based on Super-SBM and panel regression models. Ecological Indicators. 86, 67-80. 10.1016/j.ecolind.2017.12.011

Zhou L., Zhou C., Yang F., Che L., Wang B., Sun D., 2019. Spatio-temporal evolution and the influencing factors of $\mathrm{PM}_{2.5}$ in China between 2000 and 2015. Journal of Geographical Sciences. 29 (2),253-270. DOI 10.1007/s11442-019-1595-0

Zhu Q., Li X., Li F., Wu J., Zhou D., 2020. Energy and environmental efficiency of China's transportation sectors under the constraints of energy consumption and environmental pollutions. Energy Economics. 89, 104817. DOI 10.1016/j.eneco.2020.104817

About the corresponding authors Kai Liu is an associate professor at the College of Geography and Environment 
669

670

671

672

673

674

675

676

677

678

679

680

681

682

683

684

685

686

687

688

689

690

691

692

693

in Shandong Normal University. His current research interests include economic geography, regional development, environmental economics, and environmental management. He has published papers on well-known international academic journals such as Environmental Science and Pollution Research, Renewable and Sustainable Energy Reviews, Technological Forecasting and Social Change, Resources, Conservation and Recycling and so on.

Zongbin Zhang is a professor at the School of Economics in Shandong Normal University, and he is also the dean of Graduate School in Shandong Normal University. His research interests include environmental economics and regional economies. He has published papers on well-known international academic journals such as Economic Research Journal and Journal of International Trade.

Ethical approval

Not applicable.

\section{Consent to participate}

Not applicable.

\section{Consent to publish}

Not applicable.

Authors contributions

Kai Liu assessed the factors influencing urban atmospheric environmental efficiency, and was a major contributor in writing the manuscript. Xiaoyu Wang assessed the urban atmospheric environmental efficiency. Zongbin Zhang analyzed urban atmospheric environmental efficiency and factors influencing it. All authors read and approved the final manuscript.

Availability of data and material

All data generated or analyzed during this study are included in this article.

694 Clinical trials registration 
695 Not applicable. 